\title{
Understanding the early mortality benefit observed in the PARADIGM-HF trial: considerations for the management of heart failure with sacubitril/valsartan
}

This article was published in the following Dove Press journal:

Vascular Health and Risk Management

\author{
George G Sokos' \\ Amresh Raina ${ }^{2}$ \\ 'Department of Medicine, Division of \\ Cardiology, West Virginia School of \\ Medicine, Morgantown, WV, USA; \\ ${ }^{2}$ Pulmonary Hypertension Program, \\ Section of Heart Failure/Transplant/MCS \\ \& Pulmonary Hypertension, Allegheny \\ General Hospital, AGH McGinnis \\ Cardiovascular Institute, Pittsburgh, \\ PA, USA
}

\begin{abstract}
This review aims to elucidate the optimal dosing of angiotensin receptor-neprilysin inhibitor (ARNI) therapy in the heart failure (HF) treatment paradigm through examination of the trial population characteristics and the mortality benefit observed in the Prospective Comparison of ARNI with angiotensin-converting enzyme inhibitor (ACEI) to Determine Impact on Global Mortality and Morbidity in Heart Failure (PARADIGM-HF; NCT01035255) trial. Considerations regarding the initiation and titration of sacubitril/valsartan, a first-in-class ARNI, will also be addressed. The approval of sacubitril/valsartan heralded the first novel pharmacological class in over a decade for the treatment of heart failure with reduced ejection fraction (HFrEF). The PARADIGM-HF trial showed that treatment with valsartan/valsartan reduced the risk of first occurrence of either cardiovascular death or HF-related hospitalization (composite primary endpoint) by $20 \%$ compared with enalapril in patients with HFrEF. The incremental benefits of treatment with valsartan/valsartan over enalapril demonstrated in the PARADIGM-HF trial led to strong recommendations for its use over ACEIs or angiotensin receptor blockers to further reduce morbidity and mortality in the 2016 and 2017 American College of Cardiology/American Heart Association/Heart Failure Society of America updates to the guidelines for the management of HF. Although the optimal timing for the initiation of valsartan/valsartan has yet to be determined, its early use is likely to have a positive impact on patient outcomes.
\end{abstract}

Keywords: angiotensin receptor-neprilysin inhibitor, cardiovascular death, patient outcomes, treatment recommendations

\section{Introduction}

Heart failure (HF) represents a substantial health care burden in the United States, related to 1 in 9 deaths. ${ }^{1,2}$ From 2012 to 2030 , its prevalence has been projected to increase by $46 \%$, affecting more than 8 million Americans. ${ }^{1,2}$ The pathophysiologic mechanisms underlying HF development and progression are complex, predominantly involving increased activation of both the renin-angiotensin-aldosterone system (RAAS) and the sympathetic nervous system (SNS). The activation of these systems is counterbalanced by endogenous peptides (eg, natriuretic peptides), which are released in response to myocardial stretch that results from excessive neurohormonal activity. ${ }^{3-5}$

Lifestyle interventions aimed at risk reduction comprise an important strategy for preventing $\mathrm{HF}$ and delaying or reversing disease progression following its onset. $^{6}$ However, when symptomatic HF develops, pharmacotherapy is typically warranted. $^{6-8}$
Correspondence: George G Sokos Advanced Heart Failure, WVU Heart \& Vascular Institute, I Medical Center Drive, Box 8003 Morgantown, WV 26506, USA

Tel +I 3045984478

$\mathrm{Fax}+\mathrm{I} 3045984779$

Email George.Sokos@hsc.wvu.edu 
Response to pharmacologic therapies for HF differs depending on cardiac function, which is determined by measurement of ejection fraction (EF). ${ }^{6}$ Accordingly, EF has been used to classify patients as having either HF with reduced $\mathrm{EF}(\mathrm{EF} \leq 40 \%$; $\mathrm{HFrEF})$ or $\mathrm{HF}$ with preserved $\mathrm{EF}$ (EF $>50 \%$; HFpEF), although many HF clinical trials have used a lower threshold of $\mathrm{EF} \leq 35 \%$ to define HFrEF. ${ }^{6}$ In symptomatic patients with $\mathrm{HFrEF}$, pharmacologic therapies targeting the overactive RAAS and SNS become necessary. ${ }^{6,8-10}$ Agents targeting these pathways, including angiotensin-converting enzyme inhibitors (ACEIs), angiotensin receptor blockers (ARBs), $\beta$-blockers, and mineralocorticoid receptor antagonists (MRAs), have been the mainstays of HFrEF treatment since the 1990s. ${ }^{11-15}$

Although mortality rates associated with HF have improved with the development of these therapeutic options and the use of guideline-directed evaluation and management (GDEM), approximately $50 \%$ of the patients with HF still do not survive 5 years past diagnosis. ${ }^{2}$ Thus, new therapies that can further improve survival rates and patient outcomes in HFrEF are required. The aim of this review is to discuss the implications of the introduction of one such new therapy - the angiotensin receptor-neprilysin inhibitor (ARNI) pharmacological class - and to explore whether use of this therapy earlier in the HFrEF treatment paradigm may ultimately lead to an overall improvement in patient outcomes, particularly mortality.

\section{Established conventional therapies for HF}

The traditional pharmacological treatments of GDEM for HFrEF- $\beta$-blockers, ACEIs/ARBs, and MRAs ${ }^{6}$ - inhibit the activation of the SNS and RAAS, effectively resisting the development and progression of HF in two main ways: 1) control of blood pressure and left ventricular (LV) afterload and 2) reversing impairments caused by the effects of the over-activated RAAS and SNS on pathologic ventricular remodeling. ${ }^{4}$ In addition, to decrease the risk of hospitalization for HF, digoxin and/or the $I_{f}$ current inhibitor ivabradine can be added to standard GDEM in patients who have persistent symptoms of HFrEF. ${ }^{6,7}$

The goal of optimal management of comorbid hypertension is the reduction of afterload on the heart, thereby preventing the cardiac remodeling and fibrosis that results from impaired ventricular function. ${ }^{4,16}$ Studies have demonstrated that effective hypertensive control reduces the incidence of HF by approximately $50 \%$, with the most effective therapeutic classes in this regard being $\beta$-blockers, ACEIs, and diuretics. ${ }^{17}$ Even once HF is established, hypertension management remains a critical treatment goal. ${ }^{6}$ The use of $\beta$-blockers and ACEIs has also been shown to reverse impairments in LV function caused by pathologic remodeling, ${ }^{18-20}$ which has been shown to contribute to HF progression and risk of cardiovascular (CV) events. ${ }^{21,22}$ This reversal has been demonstrated in symptomatic and asymptomatic patients with LV dysfunction but no overt HFrEF. ${ }^{18-20}$ Morbidity and mortality benefits from guideline-directed pharmacological therapies for HFrEF have been demonstrated in clinical trials (summarized in Table 1).

\section{$\beta$-blockers}

$\beta$-blockers - specifically bisoprolol, carvedilol, and long-acting metoprolol-have consistently been shown to significantly and incrementally lower mortality risk when added to optimized GDEM for patients with HFrEF. ${ }^{11,12,20,23-25}$

\section{ACEls and ARBs}

Although enalapril was the first ACEI to demonstrate mortality benefits for patients with $\mathrm{HF}^{26,27}$ a meta-analysis conducted in 1995 found similar benefits with other ACEIs, including captopril, ramipril, quinapril, and lisinopril. ${ }^{6,28}$ The use of ACEIs in patients with normal or controlled blood pressure, but who are at high risk for developing HF (stage A HF), has also been shown to reduce the risk for developing $\mathrm{HF}^{29}$ as was observed in the Studies of Left Ventricular Dysfunction (SOLVD) prevention trial (NCT00000516). ${ }^{30}$ In this trial, patients with asymptomatic LV dysfunction had an annualized $10 \%$ risk for developing $\mathrm{HF}$ and an $8 \%$ risk for death or HF-related hospitalization despite the absence of significant symptoms. Intervention with the ACEI enalapril versus placebo at this early stage, prior to development of overt HF, prevented the development of HF and improved clinical outcomes in patients with LV dysfunction. ${ }^{30}$

In 2000, losartan became the first ARB to demonstrate similar mortality benefits and improved tolerability compared with ACEIs in patients with New York Heart Association (NYHA) class II-IV HFrEF. ${ }^{14,27}$ Soon after, the addition of the ARB valsartan to background therapy (which included an ACEI in approximately $83 \%$ of the patients) was also shown to reduce the risk for the combined endpoint of morbidity and mortality compared with placebo, although it did not reduce the risk for all-cause mortality. ${ }^{31}$ However, the high number of discontinuations with ARB therapy added to ACEI therapy led to recommendations against their combined use. ${ }^{6,31,32}$ Accordingly, treatment with ARBs is typically recommended for 
Table I Morbidity and mortality benefits of pharmacologic therapies for heart failure

\begin{tabular}{|c|c|c|}
\hline Pharmacological therapy & Mortality endpoint & Other key endpoints \\
\hline \multicolumn{3}{|l|}{$\beta$-blockers } \\
\hline Carvedilol vs placebo"' & $\mathrm{RR}, 0.35 ; 95 \% \mathrm{Cl}, 0.20-0.6 \mathrm{I} ; \mathrm{P}<0.00 \mathrm{I}$ & $\begin{array}{l}\text { Mortality or hospitalization for CV disease: } \mathrm{RR}, 0.62 ; 95 \% \mathrm{Cl}, 0.47-0.82 \text {; } \\
P<0.00 \mathrm{I}\end{array}$ \\
\hline $\begin{array}{l}\text { Metoprolol CR/XL vs } \\
\text { placebo } 12\end{array}$ & $\mathrm{RR}, 0.66 ; 95 \% \mathrm{Cl}, 0.53-0.8 \mathrm{I} ; P=0.00009$ & CV-related mortality: $R R, 0.62 ; 95 \% \mathrm{Cl}, 0.50-0.78 ; P=0.00003$ \\
\hline Bisoprolol vs placebo ${ }^{23}$ & $\mathrm{HR}, 0.66 ; 95 \% \mathrm{Cl}, 0.54-0.8 \mathrm{I} ; \mathrm{P}<0.000 \mathrm{I}$ & $\begin{array}{l}\text { CV death or CV-related hospitalization: HR, } 0.79 ; 95 \% \\
C l, 0.69-0.90 ; P=0.0004\end{array}$ \\
\hline \multicolumn{3}{|l|}{ ACEls } \\
\hline Enalapril vs placebo ${ }^{26}$ & $R R, 0.73 ; P=0.003$ & Mortality due to HF: RR, $0.50 ; P<0.00 \mathrm{I}$ \\
\hline Enalapril vs placebo ${ }^{15}$ & $\mathrm{RR}, 0.84 ; 95 \% \mathrm{Cl}, 0.74-0.95 ; P<0.0072$ & Mortality or HFH: RR, $0.74 ; 95 \% \mathrm{Cl}, 0.66-0.82 ; P<0.00 \mathrm{I}$ \\
\hline \multicolumn{3}{|l|}{ ARBs } \\
\hline Losartan vs captopril $^{14}$ & $\mathrm{HR} ; \mathrm{I} .13 ; 95.7 \% \mathrm{Cl}, 0.95-1.35 ; P=0.16$ & Mortality or hospitalization: HR, I.07; $95 \% \mathrm{Cl}, 0.97-1.19 ; P=0.18$ \\
\hline Valsartan vs placebo ${ }^{31}$ & RR, I.02; 98\% Cl, 0.88-I.I8; $P=0.80$ & Morbidity or mortality: RR, $0.87 ; 97.5 \mathrm{Cl}, 0.77-0.97 ; P=0.009$ \\
\hline \multicolumn{3}{|l|}{ MRAs } \\
\hline Spironolactone vs placebo ${ }^{13}$ & RR, 0.70; $95 \% \mathrm{Cl}, 0.60-0.82 ; P<0.00 \mathrm{I}$ & $\begin{array}{l}\text { Cardiac-related mortality or hospitalization: } \mathrm{RR}, 0.68 ; 95 \% \\
\mathrm{Cl}, 0.59-0.78 ; P<0.00 \mathrm{I}\end{array}$ \\
\hline Eplerenone vs placebo ${ }^{33}$ & $\begin{array}{l}\text { Adjusted HR, } 0.76 ; 95 \% \mathrm{Cl}, 0.62-0.93 \\
P=0.008\end{array}$ & $\begin{array}{l}\text { CV-related mortality or HFH: adjusted HR, } 0.63 ; 95 \% \\
C l, 0.54-0.74 ; P<0.00 \mathrm{I}\end{array}$ \\
\hline \multicolumn{3}{|l|}{ Cardiac glycoside } \\
\hline Digoxin vs placebo ${ }^{34}$ & $\mathrm{RR}, 0.99 ; 95 \% \mathrm{Cl}, 0.9 \mathrm{I}-\mathrm{I} .07 ; P=0.80$ & $\begin{array}{l}\text { Hospitalization for worsening HF: RR, } 0.72 ; 95 \% \mathrm{Cl}, 0.66-0.79 \text {; } \\
P<0.00 \mathrm{I}\end{array}$ \\
\hline \multicolumn{3}{|l|}{ HCN channel blocker } \\
\hline Ivabradine vs placebo ${ }^{36}$ & $\mathrm{HR}, 0.90 ; 95 \% \mathrm{Cl}, 0.80-1.02 ; P=0.092$ & $\begin{array}{l}\mathrm{CV} \text { death or hospitalization for worsening HF: HR, } 0.82 ; 95 \% \\
\mathrm{Cl}, 0.75-0.90 ; P<0.000 \mathrm{I}\end{array}$ \\
\hline \multicolumn{3}{|l|}{ ARNI } \\
\hline $\begin{array}{l}\text { valsartan/valsartan vs } \\
\text { enalapril }\end{array}$ & $\mathrm{HR}, 0.84 ; 95 \% \mathrm{Cl}, 0.76-0.93 ; P<0.00 \mathrm{I}$ & $\begin{array}{l}\text { CV-related mortality or first HFH: HR, } 0.80 ; 95 \% \mathrm{Cl}, 0.73-0.87 \text {; } \\
P<0.00 \mathrm{I}\end{array}$ \\
\hline $\begin{array}{l}\text { Sacubitril/valsartan vs } \\
\text { enalapril }^{64}\end{array}$ & $\begin{array}{l}\mathrm{HR}, 0.66 ; 95 \% \mathrm{Cl}, 0.30-\mathrm{I} .48 ; P \text { not } \\
\text { reported }\end{array}$ & $\begin{array}{l}\text { Composite of serious clinical events: }{ }^{\mathrm{a}} \mathrm{HR}, 0.54 ; 95 \% \mathrm{Cl}, 0.37-0.79 \text {; } \\
P \text { not reported }\end{array}$ \\
\hline
\end{tabular}

Notes: ${ }^{a}$ This endpoint included death, rehospitalization for heart failure, implantation of a left ventricular device, and inclusion on the list of patients eligible for heart transplantation.

Abbreviations: ACEl, angiotensin-converting enzyme inhibitor; ARB, angiotensin receptor blocker; ARNI, angiotensin receptor-neprilysin inhibitor; Cl, confidence interval; $\mathrm{CR}$, controlled-release; CV, cardiovascular; $\mathrm{HCN}$, hyperpolarization-activated cyclic nucleotide; HF, heart failure; HFH, heart failure hospitalization; HR, hazard ratio; MRA, mineralocorticoid receptor antagonist; RR, relative risk; $X L$, extended-release.

patients unable to receive ACEIs, due to poor tolerance or contraindications to therapy. ${ }^{6-8}$

\section{MRAs}

MRAs are recommended in patients with NYHA class IIIV HFrEF to reduce morbidity and mortality unless contraindications are present. $^{6}$ Mortality benefits were first observed in 1999 with spironolactone, and subsequently, in 2011 with eplerenone. ${ }^{13,33}$ The overwhelming benefits observed with eplerenone for reducing mortality and hospitalization risks support introducing an MRA earlier in the continuum of HF progression, consistent with guideline recommendations. ${ }^{6,33}$

\section{Digoxin}

Digoxin is recommended to reduce risk of HF hospitalization for patients with HFrEF who continue to experience persistent symptoms during GDEM or for patients with severe symptoms at initial presentation who have not yet responded symptomatically to GDEM. ${ }^{6}$ In clinical trials, 
long-term treatment with digoxin has not been shown to decrease risk of mortality, but modest reductions have been observed for risks of composite endpoints, including hospitalization for HF and $\mathrm{CV}$ or HF mortality. ${ }^{34,35}$

\section{Ivabradine}

Ivabradine is a specific inhibitor of the $I_{f}$ current in the sinusoidal node that is recommended to reduce risk of hospitalization for HF in patients with NYHA class II-III HFrEF who are receiving GDEM that includes a $\beta$-blocker at the maximally tolerated dose and who are in sinus rhythm with a resting heart rate $\geq 70 \mathrm{bpm} .^{7,8}$ Ivabradine has been shown to reduce the risk of the composite endpoint of $\mathrm{CV}$ death or HF hospitalization in patients with HFrEF, but statistical significance was not reached compared with placebo for reduction in all-cause mortality. ${ }^{36}$

\section{Sacubitril/valsartan and the PARADIGM-HF trial}

\section{Sacubitril/valsartan: the first ARNI}

Even among patients receiving standard-of-care management, HFrEF continues to be associated with high rates of mortality, as the disease typically progresses despite treatment. $^{2,37,38}$ The number of deaths attributable to HF was approximately as high in 2013 as it was in 1995, likely due to the lack of therapeutic advancements. A number of novel treatments have been investigated to improve clinical outcomes for patients with $\mathrm{HF}$. Sacubitril/valsartan is the first-in-class ARNI for the treatment of HFrEF. ${ }^{7,39}$ The inhibition of neprilysin prevents the breakdown of endogenous compensatory peptides, including the natriuretic peptides (ie, ANP, BNP, CNP) and angiotensin II, allowing them to exert their mitigating effects. ${ }^{40}$ Neprilysin inhibition from the sacubitril component complements the blockade of angiotensin receptors with valsartan to synergistically improve clinical outcomes in patients with HFrEF compared with standalone RAAS inhibition. ${ }^{40-42}$

The ARNI sacubitril/valsartan was approved in 2015 by the US Food and Drug Administration (FDA) and the European Medicines Agency for the treatment of chronic HF and HFrEF. ${ }^{43,44}$ The granted approval was supported by the positive results of the phase 3 Prospective Comparison of ARNI with ACEI to Determine Impact on Global Mortality and Morbidity in Heart Failure (PARADIGM-HF; NCT01035255) trial (Table 1). ${ }^{45}$

\section{Additional findings from the PARADIGM-HF trial}

In an extrapolation of survival data from the PARADIGMHF trial, it was projected that the long-term treatment effect of sacubitril/valsartan could be a mean increase in survival time of 1.4 years for a 55-year-old patient and 1.3 years for a 65-year-old patient-higher than any increase imparted by enalapril treatment. ${ }^{46}$ Furthermore, a pharmacoeconomic analysis suggested that, compared with the ACEI lisinopril, sacubitril/valsartan treatment provided 0.69 additional life-years and 0.62 additional qualityadjusted life-years. ${ }^{47}$ This evidence highlights the value of adding ARNIs in place of ACEIs - when not contraindicated - in the treatment of HFrEF. A detailed analysis of the mode of death in the PARADIGM-HF trial showed that, compared with enalapril, sacubitril/valsartan also reduced the risk for sudden cardiac death and death due to worsening HF (Figure 1), whereas the risk for death attributed to stroke or myocardial infarction was not significantly affected. ${ }^{48}$ The observation of reduced risk of sudden cardiac death with sacubitril/valsartan is noteworthy given the relatively low rate $(\sim 15 \%)$ of implantable cardioverter-defibrillator (ICD) use in the trial, which was in line with clinical practice. ${ }^{45,49}$

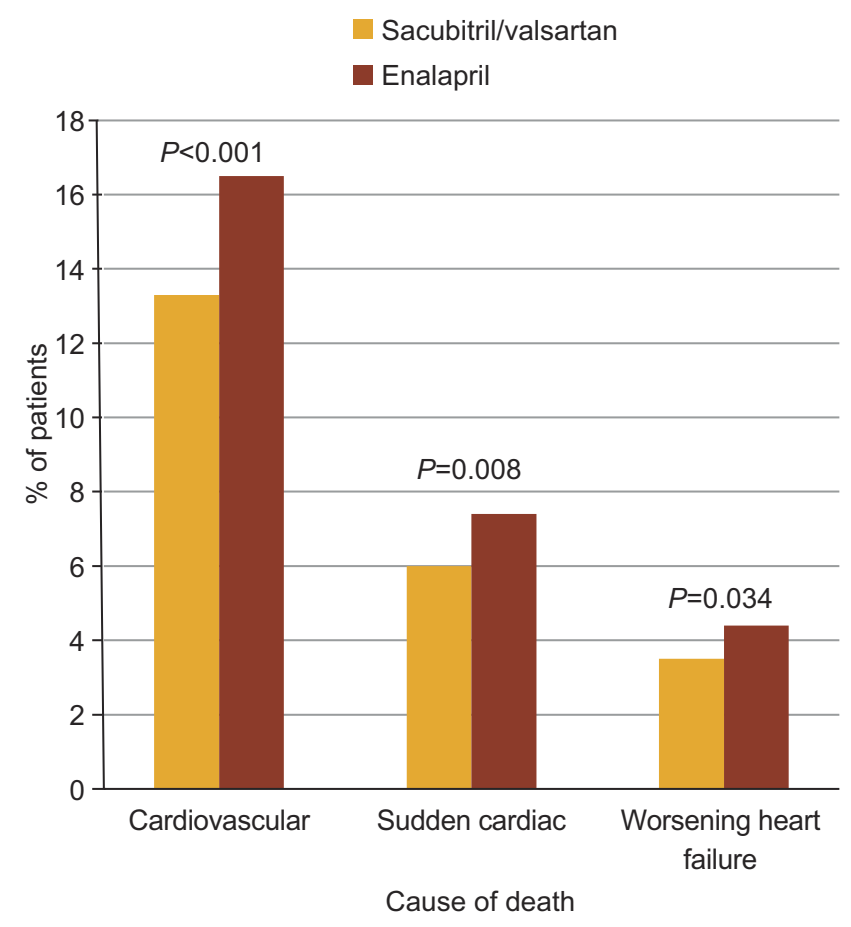

Figure I Rates of death by cause and treatment from PARADIGM-HF. Note: Data from Desai et al. ${ }^{48}$

Abbreviation: PARADIGM-HF, Prospective Comparison of ARNI with ACEI to Determine Impact on Global Mortality and Morbidity in Heart Failure. 
The mechanism by which sacubitril/valsartan reduces CV mortality is not fully understood. However, it has been hypothesized that neprilysin inhibition may reduce the risk for fatal ventricular arrhythmias (which are a common cause of sudden cardiac death) by reducing myocardial fibrosis and ventricular hypertrophy or attenuating progressive ventricular remodeling. ${ }^{48}$ Hyperkalemia is also a known risk factor for CV mortality and sudden cardiac death. ${ }^{50,51}$ Thus, it is plausible that some of the reduced mortality benefits associated with sacubitril/valsartan could be associated with reduced risk of hyperkalemia compared with enalapril (discussed in detail below), ${ }^{45}$ possibly as a result of membrane stabilization.

Improvements in safety outcomes were also observed in the PARADIGM-HF trial. ${ }^{45}$ Hyperkalemia (serum potassium $>6.0 \mathrm{mmol} / \mathrm{L}$ ) was observed less frequently in patients receiving sacubitril/valsartan (4.3\%) than in patients taking enalapril (5.6\%); however, the incidence of symptomatic hypotension was higher in the sacubitril/valsartan group (14.0\%) than in the enalapril group $(9.2 \%){ }^{45}$ Other adverse events that were observed less frequently with sacubitril/valsartan compared with enalapril included cough (11.3\% vs $14.3 \%)$ and elevated serum creatinine ( $\geq 2.5 \mathrm{mg} / \mathrm{dL} ; 3.3 \%$ vs $4.5 \%) .{ }^{45}$ Angioedema was reported in 19 patients receiving sacubitril/valsartan and 10 patients receiving enalapril. Additionally, fewer patients discontinued sacubitril/valsartan than discontinued enalapril because of an adverse event (10.7\% vs $12.3 \%$ ) or renal impairment $(0.7 \%$ vs $1.4 \%) .{ }^{45}$ Neprilysin inhibition and RAAS blockade have also been shown to be renal protective in a meta-analysis of 4 studies, including the PARADIGM-HF and Prospective Comparison of ARNI with ARB on Management of Heart Failure with Preserved Ejection Fraction (PARAMOUNT; NCT00887588) trials (sacubitril/valsartan in HFrEF and HFpEF, respectively) and the International Multicentre Prevalence Study on Sepsis (IMPRESS) and Omapatrilat Versus Enalapril Randomized Trial of Utility in Reducing Events (OVERTURE) studies (omapatrilat in HFrEF). ${ }^{52}$ This analysis showed that the synergistic effect of inhibiting neprilysin and the RAAS provides a $32 \%$ reduction in the risk of decline in renal function, defined as: 1) elevated serum creatinine or 2) $>50 \%$ reduction in glomerular filtration rate, over a mean follow-up time of 51 weeks. ${ }^{52}$

Patients receiving sacubitril/valsartan were also less likely to experience worsening of NYHA functional class within 8 months of randomization versus those receiving enalapril (5.4\% vs $7.0 \% ; P=0.004) .{ }^{53}$ Likewise, fewer patients receiving treatment with valsartan/valsartan compared with those receiving enalapril experienced symptom worsening, as measured by a $\geq 5$-point reduction in the Kansas City
Cardiomyopathy Questionnaire (KCCQ) total symptom score within 4 months ( $25.1 \%$ vs $28.3 \%$; $P=0.002), 8$ months ( $28.2 \%$ vs $31.8 \% ; P=0.001)$, and 12 months $(29.0 \%$ vs $31.5 \%$; $P=0.03$ ) of randomization (Figure 2) ${ }^{53}$ Among patients who did experience clinical progression, significantly fewer patients receiving sacubitril/valsartan versus enalapril required intensification of therapy for HF (ie, addition of a new drug, intravenous therapy, or increase in diuretic dose; hazard ratio (HR), $0.84 ; 95 \%$ confidence interval (CI), 0.74-0.94; $P=0.003){ }^{53}$

Treatment with sacubitril/valsartan also resulted in reduced hospitalization rates. In the PARADIGM-HF trial, hospitalization due to worsening HF was $23 \%$ less likely for patients treated with sacubitril/valsartan compared with enalapril (HR, 0.77; 95\% CI, 0.67-0.89; $P<0.001)$; the difference between treatment groups was evident as early as 30 days after randomization. ${ }^{53}$ This finding is particularly important because hospitalization due to acute decompensation is associated with disease progression. Data from studies of patients hospitalized for acute HF suggest a subsequent increased post-discharge mortality risk compared with those who were hospitalized for other reasons or not at all. ${ }^{54,55}$ Of note, the episodes of acute decompensation observed in PARADIGM-HF were less severe for patients treated

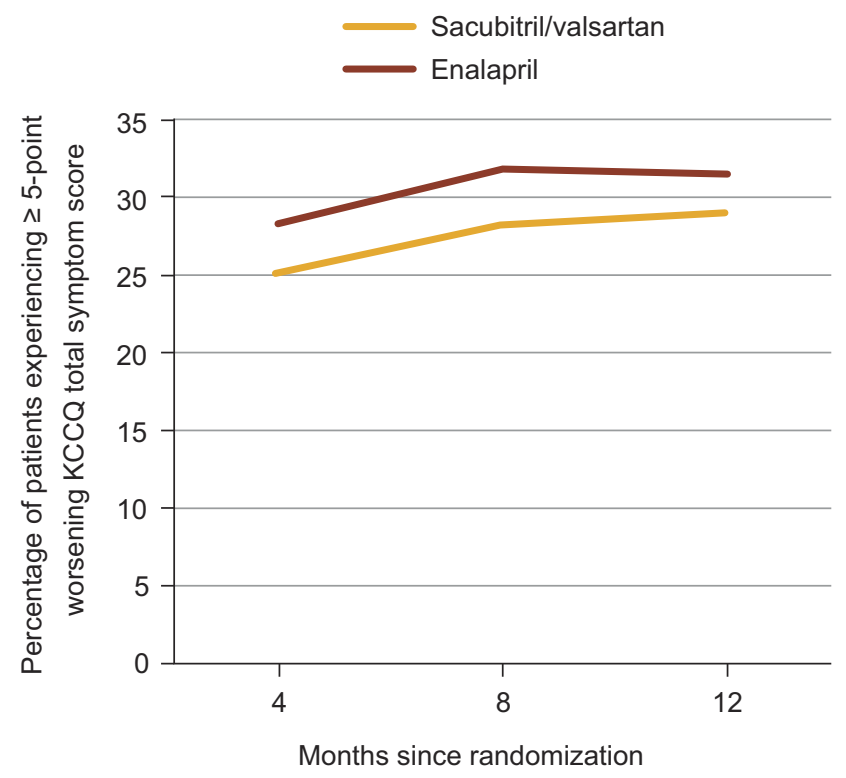

Figure 2 Comparison of patient-reported symptoms over time between treatment groups in PARADIGM-HF.

Note: Data from Packer et al. ${ }^{53}$

Abbreviations: ACEl, angiotensin-converting enzyme inhibitor; ARNI, angiotensin receptor-neprilysin inhibitor; KCCQ, Kansas City Cardiomyopathy Questionnaire; PARADIGM-HF, Prospective Comparison of ARNI with ACEI to Determine Impact on Global Mortality and Morbidity in Heart Failure. 
with sacubitril/valsartan compared with enalapril. Among surviving patients from the PARADIGM-HF trial who were hospitalized, those receiving sacubitril/valsartan versus enalapril were less likely to need intensive care (HR, 0.87; 95\% CI, 0.78-0.98; $P=0.019)$ or intravenous positive inotrope therapy (HR, $0.69 ; 95 \% \mathrm{CI}, 0.57-0.85 ; P<0.001$ ), and also had a decreased risk for visiting the emergency department due to HF (HR, 0.66; 95\% CI, 0.52-0.85; $P=0.001){ }^{53}$

Similarly, repeated hospitalization for HF has been associated with worse post-discharge outcomes. ${ }^{56}$ Compared with enalapril, sacubitril/valsartan therapy reduced the rates of 30-day rehospitalization for any cause $(21.0 \%$ vs $17.8 \%$, respectively; $P=0.031$ ) and of 30-day rehospitalization for HF (13.4\% vs 9.7\%; $P=0.006) .{ }^{57}$ Overall, patients treated with sacubitril/valsartan were $29 \%$ less likely to be repeatedly hospitalized for HF compared with those treated with enalapril $(P=0.001){ }^{53}$

The early mortality benefit observed with sacubitril/ valsartan in the PARADIGM-HF trial

An important finding from the PARADIGM-HF trial was that the mortality benefit with sacubitril/valsartan was conferred early during treatment, as reflected by the early and persistent divergence of sacubitril/valsartan from enalapril on Kaplan-Meier curves for both the combined primary outcome (ie, CV death or hospitalization for HF) and for $\mathrm{CV}$ death alone (Figure 3 ). ${ }^{45}$

This early mortality benefit was sustained throughout treatment, as the difference in favor of sacubitril/valsartan for the primary outcome was observed at each of the interim analysis time points. ${ }^{45}$ The trial was stopped early after a median follow-up of only 27 months for reaching the statistical threshold of an overwhelming benefit prior to the anticipated end of the trial.

The precise mechanisms by which sacubitril/valsartan prevents or delays $\mathrm{CV}$ death are uncertain; however, emerging evidence suggests that the beneficial effects of this therapy are related to specific amelioration of HF disease pathways. In a pharmacodynamics study of patients with HFrEF who received sacubitril/valsartan, plasma levels of aldosterone, endothelin-1, and N-terminal-proBNP (NTproBNP) were significantly decreased after 21 days of treatment (all $P<0.05$ ), suggesting an early hemodynamic benefit from ARNI therapy. ${ }^{58}$
The 2016 and 2017 American College of Cardiology (ACC)/American Heart Association (AHA)/Heart Failure Society of America (HFSA) guideline updates The early clinical benefits associated with sacubitril/valsartan underscore the importance of its initiation early in the $\mathrm{HF}$ treatment paradigm. Accordingly, the 2016 and 2017 ACC/ AHA/HFSA guideline updates added ARNIs to the list of recommended drugs to reduce HF morbidity and mortality risks for patients with chronic HFrEF, irrespective of prior therapy, and did not specify different recommendations for those who are naïve to therapy with ACEIs or ARBs. ${ }^{7,8}$ Furthermore, the guidelines recommend the replacement of ACEI or ARB therapy that is tolerated by patients with chronic symptomatic NYHA class II or III HFrEF with ARNI therapy to further reduce morbidity and mortality. The recommendation to switch from the standard of care to this novel pharmacologic class in patients with NYHA class II or III HFrEF, in particular, is in recognition of the value of the early use of ARNI therapy. These guidelines also offer important safety considerations for the use of ARNI therapy; specifically, that it should not be used concomitantly (or within $36 \mathrm{hrs}$ ) of a dose of an ACEI and that it should not be prescribed to patients with a history of angioedema.

\section{Sacubitril/valsartan post-approval experience and implementation in clinical practice Target patient profile}

To translate the benefits associated with sacubitril/valsartan therapy seen in the PARADIGM-HF trial into clinical practice, the target patient populations for this treatment should be identified. This is accomplished by: 1) comparing the patient's clinical profile with the indications, contraindications, and safety warnings stated in the approved prescribing information for the prescriber's jurisdiction; ${ }^{39}$ 2) by considering the expert guidance of the American and/or European cardiology guidelines on all appropriate treatment options for this patient; $;^{7,8,59}$ and 3) by evaluating the patient's characteristics in comparison to those of patients enrolled in the PARADIGM-HF trial (Table 2).

Baseline and demographic characteristics of patients from the PARADIGM-HF trial are summarized in Table 2. Despite use of GDEM recommended at the time, patients exhibited persistent signs and symptoms of HF. ${ }^{60}$ As discussed previously, approximately $15 \%(n=1243)$ of enrolled 
A

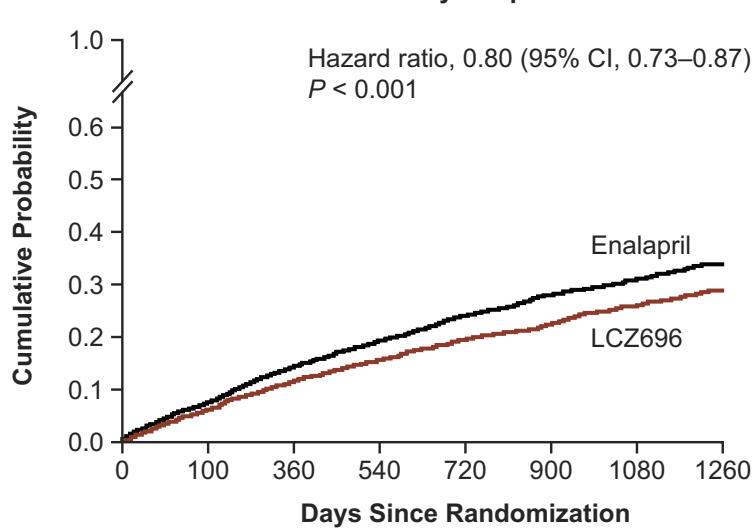

No. at Risk

$\begin{array}{lllllllll}\text { LCZ696 } & 4187 & 3922 & 3663 & 3018 & 2257 & 1544 & 896 & 249\end{array}$

$\begin{array}{lllllllll}\text { Enalapril } & 4212 & 3883 & 3579 & 2922 & 2123 & 1488 & 853 & 236\end{array}$

B

Death From Cardiovascular Causes

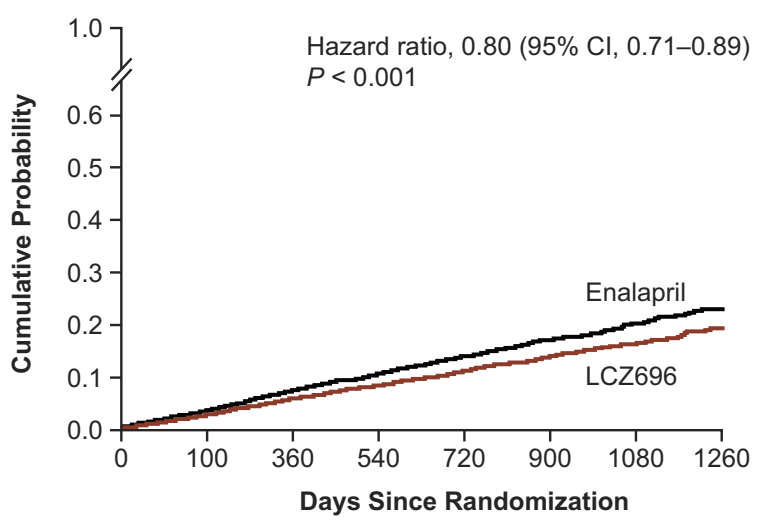

No. at Risk

$\begin{array}{lllllllll}\text { LCZ696 } & 4187 & 4056 & 3891 & 3282 & 2478 & 1716 & 1005 & 280\end{array}$

$\begin{array}{lllllllll}\text { Enalapril } & 4212 & 4051 & 3860 & 3231 & 2410 & 1726 & 994 & 279\end{array}$

Figure 3 PARADIGM-HF Kaplan-Meier curves for the primary endpoint (A) and death from cardiovascular causes (B), according to study group.

Notes: From N Engl J Med, McMurray JJ, Packer M, Desai AS, et al, Angiotensin-neprilysin inhibition versus enalapril in heart failure, 37I(II):993-I004. Copyright@ (2014) Massachusetts Medical Society. Adapted with permission from Massachusetts Medical Society. ${ }^{45}$

Abbreviations: ACEl, angiotensin-converting enzyme inhibitor; ARNI, angiotensin receptor-neprilysin inhibitor; Cl, confidence interval; LCZ696, sacubitril/valsartan; PARADIGM-HF, Prospective Comparison of ARNI with ACEI to Determine Impact on Global Mortality and Morbidity in Heart Failure.

patients had an ICD. ${ }^{45}$ Although this number is relatively low, it is comparable to the percentage of patients with an ICD enrolled in previous HF trials. ${ }^{60}$ Moreover, only approximately $50 \%$ of the eligible patients receive ICD therapy in clinical practice. ${ }^{49}$

Across the various analyses of the PARADIGM-HF trial that explored the potential effects of different patient characteristics on treatment benefits, very little heterogeneity in the sacubitril/valsartan treatment outcomes was observed. An examination of the PARADIGM-HF trial results by age showed similar benefits with sacubitril/valsartan over enalapril therapy across the broad range of ages (18-96 years) entered in the trial, even after adjustment for baseline differences. ${ }^{61}$ Based on the post hoc analysis of PARADIGM-HF trial results by baseline EF, which ranged from $5 \%$ to $42 \%$, the degree of $\mathrm{LV}$ dysfunction also did not appear to impact outcomes. ${ }^{62}$ Therefore, patient age and degree of LV dysfunction should not be a priori factors considered for the selection of patients who may benefit from ARNI therapy.

Although most patients in the PARADIGM-HF trial had mild HF symptoms according to NYHA classification, numerous patients in the trial were at high risk for adverse outcomes when evaluated according to HF risk scores, including the Meta-Analysis Global Group in Chronic Heart Failure (MAGGIC) and the Eplerenone in Mild Patients Hospitalization and Survival Study in Heart Failure (EMPHASIS-HF) risk scores. ${ }^{63}$ The benefits of sacubitril/ valsartan in the PARADIGM-HF trial were observed across all risk categories, with the greatest absolute benefit reported in patients deemed to be at highest risk.

Although this discourse has advocated the selection of patients having characteristics resembling the PARADIGMHF trial population, it is important to note that the approved prescribing information may include patients who would have been excluded from the PARADIGM-HF trial. For example, the FDA approved sacubitril/valsartan for the treatment of patients naïve to ACEIs and ARBs, although such patients were excluded from the PARADIGM-HF trial. ${ }^{39,45}$ Similarly, the benefits of sacubitril/valsartan therapy observed in populations composed mostly of patients with NYHA class II HFrEF could be extrapolated to suggest that its use early in the disease process is likely to have a positive impact on clinical outcomes. Ideally, cardiologists would treat HFrEF immediately following the onset of symptoms; however, the optimal timing for the initiation of sacubitril/valsartan has yet to be determined . Hospitalization presents an opportunity for the initiation of sacubitril/valsartan therapy once patients are stabilized. The safety and efficacy of this approach cannot be determined from the results of the PARADIGM-HF trial, as this trial did not include patients recently hospitalized for HF (due to the requirement for patients to be taking stable doses of a $\beta$-blocker and an ACEI or ARB for at least 4 weeks prior to randomization). To support recommendations regarding the use of sacubitril/valsartan therapy following hospitalization for HF, the Comparison of Sacubitril/valsartan Versus Enalapril on Effect 
Table 2 Identification of candidates for sacubitril/valsartan treatment

\begin{tabular}{|c|c|}
\hline & PAR \\
\hline & 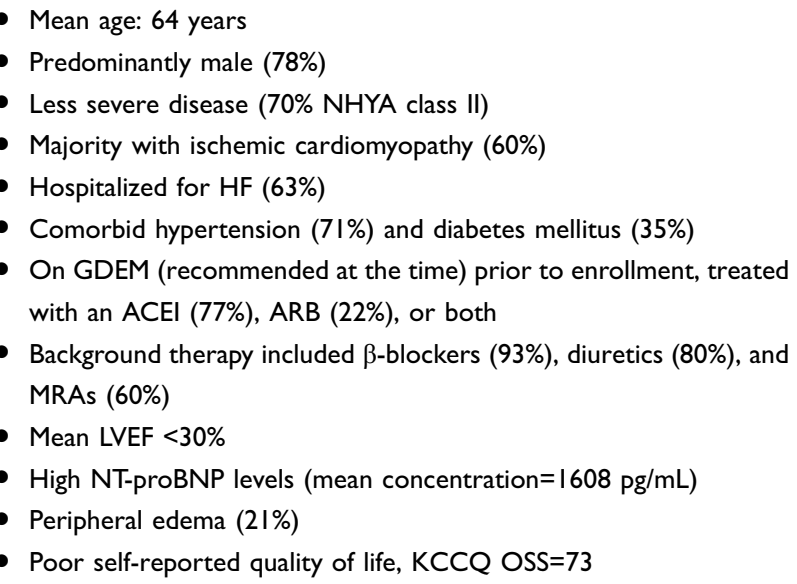 \\
\hline & Evidenc \\
\hline & $\begin{array}{l}\text { - Patients with HFrEF } \\
\text { - Patients with mild-to-moderate chronic HF, eg, NYHA class II-III } \\
\text { - Patients with stable HF already receiving guideline-directed therapy } \\
\text { in other pharmacologic classes, as appropriate ( } \beta \text {-blocker and MRA) } \\
\text { - Systolic blood pressure } \geq 100 \mathrm{mmHg} \\
\text { - eGFR } \geq 30 \mathrm{~mL} / \mathrm{min} / 1.73 \mathrm{~m}^{2} \\
\text { - Potassium } \leq 5.2 \mathrm{mmol} / \mathrm{L}\end{array}$ \\
\hline & $\begin{array}{l}\text { Evidence insufficient or not available to currently } \\
\text { recommend treatment }\end{array}$ \\
\hline & $\begin{array}{l}\text { - Patients with HFpEF } \\
\text { - Patients with severe HF, eg, NYHA class IV } \\
\text { - Hospitalized patients with acute decompensated HF } \\
\text { - Patients with specific disease etiology or comorbidity }\end{array}$ \\
\hline & ontraindicated for treatment \\
\hline & $\begin{array}{l}\text { - History of angioedema related to previous ACEI or ARB therapy } \\
\text { - Concomitant use of ACEI or other ARB } \\
\text { - Concomitant use of aliskiren in patients with diabetes mellitus } \\
\text { - Severe hepatic impairment }\end{array}$ \\
\hline
\end{tabular}

Notes: a Data from these studies. ${ }^{7,8,39,45,60}$

Abbreviations: ACEI, angiotensin-converting enzyme inhibitor; ARB, angiotensin II receptor blocker; ARNI, angiotensin receptor-neprilysin inhibitor; eGFR, estimated glomerular filtration rate; GDEM, guideline-directed evaluation and management; HF, heart failure; HFpEF, HF with preserved ejection fraction; HFrEF, HF with reduced ejection fraction; KCCQ OSS, Kansas City Cardiomyopathy Questionnaire overall summary score; LVEF, left ventricular ejection fraction; MRA, mineralocorticoid receptor antagonist; NT-proBNP, N-terminal pro-B-type natriuretic peptide; NYHA, New York Heart Association; PARADIGM-HF, Prospective Comparison of ARNI with ACEl to Determine Impact on Global Mortality and Morbidity in Heart Failure.

on NT-proBNP in Patients Stabilized From an Acute Heart Failure Episode (PIONEER-HF; NCT02554890) trial compared the efficacy and safety of sacubitril/valsartan and enalapril in patients who were hospitalized for acute decompensated HF and were hemodynamically stable prior to initiating treatment. ${ }^{64}$ Sacubitril/valsartan therapy provided a significantly greater reduction in levels of NT-proBNP than enalapril, with a difference between treatment groups evident as early as week 1 . In addition, the risk of the composite endpoint of serious clinical events (death, rehospitalization for HF, planned implantation of a left ventricular device, and listing for heart transplant) was lower in patients receiving sacubitril/valsartan compared with enalapril. The effect of inpatient sacubitril/ valsartan therapy following an ischemic insult and revascularization (peri-myocardial infarction) or post-myocardial infarction evaluated by the Prospective ARNI vs ACE Inhibitor Trial to Determine Superiority in Reducing Heart Failure Events After MI (PARADISE-MI; NCT02924727) ${ }^{65}$ trial.

\section{Dosing considerations}

In the PARADIGM-HF trial, achievement and maintenance of the target doses of sacubitril/valsartan (97/103 mg twice daily) and enalapril (10 $\mathrm{mg}$ twice daily) were attempted, with mean total daily doses of sacubitril/valsartan $(375 \mathrm{mg})$ and enalapril (18.9 $\mathrm{mg}$ ) close to target at the last study assessment. ${ }^{45}$ However, achieving and maintaining the target dose of an ACEI or sacubitril/valsartan can be challenging in some patient populations. ${ }^{6}$ Among hospitalized patients with acute decompensated HF enrolled in the recent PIONEERHF trial, $55.2 \%$ in the sacubitril/valsartan group and $60.8 \%$ in the enalapril group were receiving the target dose of the assigned trial drug by week $8 .{ }^{64}$ Although it may take longer than 2 weeks for some patients to tolerate titration up to the target dose, ultimately, perseverance to achieve that target is important to obtain maximal therapeutic benefit. ${ }^{6}$ In a post hoc analysis of the PARADIGM-HF trial, dose reductions by any amount in either treatment group were associated with a higher risk for the primary outcome of $\mathrm{CV}$ death or HFrelated hospitalization (HR 2.5; 95\% CI, 2.2-2.7). ${ }^{66}$ Nonetheless, patients who received treatment with lowerthan-target doses of sacubitril/valsartan still experienced a significant benefit compared with patients who received treatment with lower-than-target doses of enalapril (HR 0.80; $95 \%$ CI, 0.70-0.93). ${ }^{66}$

The proportion of patients who required a dose reduction in the PARADIGM-HF trial was similar between the enalapril (43\%) and sacubitril/valsartan (42\%) groups, and the reasons for dose reduction were generally similar; however, significantly more patients taking enalapril required dose reduction due to cough $(4.3 \%$ vs $1.8 \% ; P<0.001)$ or hypotension $(21.7 \%$ vs $16.3 \% ; P<0.001) .{ }^{66}$ Serum creatinine concentration was the best predictor of trial medication dose reduction (odds ratio 2.38; 95\% CI, 2.01-2.82), ${ }^{66}$ as explained by the relation of 
renal function to common adverse events, including hyperkalemia, hypotension, and angioedema. Permanent discontinuation of treatment was rare, irrespective of therapy. ${ }^{45}$ In many cases, patients on either treatment were successfully re-uptitrated to a higher dose; however, more patients on sacubitril/ valsartan were successfully re-uptitrated versus those on enalapril following hypotension ( $36 \%$ vs $27 \% ; P=0.026$ ) or renal dysfunction ( $41 \%$ vs $28 \% ; P=0.018) .{ }^{66}$

The recent Multicenter, Randomized, Double-blind, Parallel Group Study to Assess the Safety and Tolerability of Initiating LCZ696 in Heart Failure Patients Comparing Two Titration Regimens (TITRATION; NCT01922089) compared the tolerability of initiating and titrating sacubitril/valsartan with a condensed (49/51 mg twice daily for 2 weeks, followed by $97 / 103 \mathrm{mg}$ twice daily) versus conservative schedule (24/26 mg twice daily for 2 weeks, followed by 49/51 mg twice daily for 3 weeks, then $97 / 103 \mathrm{mg}$ twice daily) in patients with varying levels of prior ACEI or ARB exposure. ${ }^{67}$ Notably, this trial differed from the PARADIGM-HF trial because it included ACEI-naïve, ARB-naïve patients. ${ }^{67}$ In the TITRATION trial, $78 \%$ and $84 \%$ of the patients on condensed versus conservative initiation schedules, respectively, successfully achieved and maintained the target dose of 97/103 mg sacubitril/valsartan twice daily for 12 weeks. ${ }^{67}$ Furthermore, $83 \%$ and $87 \%$ of the patients on condensed and conservative schedules, respectively, tolerated a dose of 97/103 mg twice daily for the last 2 weeks of the 12-week period, irrespective of previous dose reductions or interruptions. ${ }^{67}$ Patients initially on low-dose ACEI or ARB therapy had significantly higher success rates with the conservative titration approach compared with the condensed titration approach (85\% vs $74 \%$; $P=0.030) .{ }^{67}$ Although the titration period is often longer in clinical practice, this trial has demonstrated that a shorter titration period is generally well tolerated and can successfully be used to achieve target doses in some patients. Similarly, short titration periods ( $\leq 1$ week) have been successful in previous ACEI and ARB clinical trials. ${ }^{14,26,68}$

\section{Conclusion}

Sacubitril/valsartan represents the first of a breakthrough class of drugs for the treatment of HF. The early mortality benefit observed with sacubitril/valsartan compared with enalapril in the PARADIGM-HF trial and the recent guideline recommendations regarding the use of an ARNI in HFrEF management make a compelling case for the early use of sacubitril/valsartan in the HF treatment paradigm.

\section{Human and animal rights and informed consent}

This article does not contain any studies with human participants or animals performed by any of the authors.

\section{Data availability}

The data used to compile this review are available in the relevant source publications.

\section{Acknowledgments}

Medical writing assistance was provided by Marcel Kuttab, PharmD, of Oxford PharmaGenesis Inc., Newtown, Pennsylvania, USA, and was funded by Novartis Pharmaceuticals Corporation, East Hanover, New Jersey, USA.

\section{Disclosure}

Dr Sokos has served on the speakers' bureaus of Bayer Pharmaceuticals, Actelion Pharmaceuticals, and Novartis Pharmaceuticals. He has served on the advisory boards of Gilead Sciences, Bayer Pharmaceuticals, and Novartis Pharmaceuticals. Dr Raina has received fees from Actelion, St. Jude, Bayer, and United Therapeutics, and has received nonfinancial support from Bellerophon and Oxford Pharmagenesis. The authors report no other conflicts of interest in this work.

\section{References}

1. Mozaffarian D, Benjamin EJ, Go AS, et al. Heart disease and stroke statistics-2015 update: a report from the American heart association. Circulation. 2015;131(4):e29-e322.

2. Mozaffarian D, Benjamin EJ, Go AS, et al. Heart disease and stroke statistics - 2016 update: a report from the American heart association. Circulation. 2016;133(4): e38-e360.

3. Lymperopoulos A, Rengo G, Koch WJ. Adrenergic nervous system in heart failure: pathophysiology and therapy. Circ Res. 2013;113 (6):739-753. doi:10.1161/CIRCRESAHA.113.300308

4. Reed BN, Street SE, Jensen BC. Time and technology will tell: the pathophysiologic basis of neurohormonal modulation in heart failure. Heart Fail Clin. 2014;10(4):543-557. doi:10.1016/j. hfc.2014.07.002

5. Iwanaga Y, Nishi I, Furuichi S, et al. B-type natriuretic peptide strongly reflects diastolic wall stress in patients with chronic heart failure: comparison between systolic and diastolic heart failure. $J \mathrm{Am}$ Coll Cardiol. 2006;47(4):742-748. doi:10.1016/j.jacc.2005.11.030

6. Yancy CW, Jessup M, Bozkurt B, et al. ACCF/AHA guideline for the management of heart failure: a report of the American college of cardiology foundation/American heart association task force on practice guidelines. J Am Coll Cardiol. 2013;62(16):e147-e239. doi:10.1016/j.jacc.2013.05.019

7. Yancy CW, Jessup M, Bozkurt B, et al. ACC/AHA/HFSA focused update of the $2013 \mathrm{ACCF} / \mathrm{AHA}$ guideline for the management of heart failure: a report of the American college of cardiology/American heart association task force on clinical practice guidelines and the heart failure society of America. J Card Fail. 2017;23(8):628-651. doi:10.1016/j.cardfail.2017.04.014 
8. Yancy CW, Jessup M, Bozkurt B, et al. ACC/AHA/HFSA focused update on new pharmacological therapy for heart failure: an update of the $2013 \mathrm{ACCF} / \mathrm{AHA}$ guideline for the management of heart failure: a report of the American college of cardiology/ American heart association task force on clinical practice guidelines and the heart failure society of America. $\mathrm{J} \mathrm{Am} \mathrm{Coll} \mathrm{Cardiol.}$ 2016;68(13):1476-1488. doi:10.1016/j.jacc.2016.05.011

9. Lindenfeld J, Albert NM, Boehmer JP, et al. HFSA 2010 comprehensive heart failure practice guideline. J Card Fail. 2010;16(6): e1-e194.

10. McMurray JJ. CONSENSUS to EMPHASIS: the overwhelming evidence which makes blockade of the renin-angiotensin-aldosterone system the cornerstone of therapy for systolic heart failure. Eur $J$ Heart Fail. 2011;13(9):929-936. doi:10.1093/eurjhf/hfr093

11. Packer M, Bristow MR, Cohn JN, et al. The effect of carvedilol on morbidity and mortality in patients with chronic heart failure. U.S. Carvedilol heart failure study group. $N$ Engl J Med. 1996;334 (21):1349-1355. doi:10.1056/NEJM199605233342101

12. Effect of metoprolol CR/XL in chronic heart failure: Metoprolol CR/ XL Randomised Intervention Trial in Congestive Heart Failure (MERIT-HF). Lancet. 1999;353(9169):2001-2007.

13. Pitt B, Zannad F, Remme WJ, et al. The effect of spironolactone on morbidity and mortality in patients with severe heart failure. Randomized aldactone evaluation study investigators. $N$ Engl $J$ Med. 1999;341(10):709-717. doi:10.1056/NEJM199909023411001

14. Pitt B, Poole-Wilson PA, Segal R, et al. Effect of losartan compared with captopril on mortality in patients with symptomatic heart failure: randomised trial-the losartan heart failure survival study ELITE II. Lancet. 2000;355(9215):1582-1587. doi:10.1016/s0140-6736(00)02 213-3

15. SOLVD Investigators. Effect of enalapril on survival in patients with reduced left ventricular ejection fractions and congestive heart failure. $N$ Engl J Med. 1991;325(5):293-302. doi:10.1056/ NEJM199108013250501

16. Kong P, Christia P, Frangogiannis NG. The pathogenesis of cardiac fibrosis. Cell Mol Life Sci. 2014;71(4):549-574. doi:10.1007/s00018013-1349-6

17. Baker DW. Prevention of heart failure. J Card Fail. 2002;8(5):333-346.

18. Konstam MA, Rousseau MF, Kronenberg MW, et al. Effects of the angiotensin converting enzyme inhibitor enalapril on the long-term progression of left ventricular dysfunction in patients with heart failure. SOLVD investigators. Circulation. 1992;86(2):431-438. doi:10.1161/ 01.cir.86.2.431

19. Doughty RN, Whalley GA, Walsh HA, et al. Effects of carvedilol on left ventricular remodeling after acute myocardial infarction: the CAPRICORN echo substudy. Circulation. 2004;109(2):201-206. doi:10.1161/01.CIR.0000108928.25690.94

20. Colucci WS, Kolias TJ, Adams KF, et al. Metoprolol reverses left ventricular remodeling in patients with asymptomatic systolic dysfunction: the REversal of VEntricular Remodeling with toprol-XL (REVERT) trial. Circulation. 2007;116(1):49-56. doi:10.1161/ CIRCULATIONAHA.106.666016

21. Konstam MA, Kramer DG, Patel AR, Maron MS, Udelson JE. Left ventricular remodeling in heart failure: current concepts in clinical significance and assessment. JACC Cardiovasc Imaging. 2011;4 (1):98-108. doi:10.1016/j.jcmg.2010.10.008

22. St John Sutton M, Pfeffer MA, Plappert T, et al. Quantitative two-dimensional echocardiographic measurements are major predictors of adverse cardiovascular events after acute myocardial infarction. The protective effects of captopril. Circulation. 1994;89(1):68-75. doi:10.1161/01. cir.89.1.68

23. The Cardiac Insufficiency Bisoprolol Study II (CIBIS-II): a randomised trial. Lancet. 1999;353(9146):9-13.

24. Shibata MC, Flather MD, Wang D. Systematic review of the impact of beta blockers on mortality and hospital admissions in heart failure. Eur J Heart Fail. 2001;3(3):351-357. doi:10.1016/s1388-9842(01) 00144-1
25. Chatterjee S, Biondi-Zoccai G, Abbate A, et al. Benefits of beta blockers in patients with heart failure and reduced ejection fraction: network meta-analysis. BMJ. 2013;346:f55. doi:10.1136/bmj.f1164

26. The CONSENSUS Trial Study Group. Effects of enalapril on mortality in severe congestive heart failure. Results of the Cooperative North Scandinavian Enalapril Survival Study (CONSENSUS). $N$ Engl $J$ Med. 1987;316(23):1429-1435. doi:10.1056/NEJM198706043162301

27. Braunwald $E$. The path to an angiotensin receptor antagonist-neprilysin inhibitor in the treatment of heart failure. $\mathrm{J} \mathrm{Am} \mathrm{Coll} \mathrm{Cardiol.}$ 2015;65(10):1029-1041. doi:10.1016/j.jacc.2015.01.033

28. Garg R, Yusuf S. For the collaborative group on ace inhibitor trials. Overview of randomized trials of angiotensin-converting enzyme inhibitors on mortality and morbidity in patients with heart failure. JAMA. 1995;273(18):1450-1456.

29. Arnold JM, Yusuf S, Young J, et al. Prevention of heart failure in patients in the Heart Outcomes Prevention Evaluation (HOPE) study. Circulation. 2003;107(9):1284-1290. doi:10.1161/01. cir.0000054165.93055.42

30. The SOLVD Investigators. Effect of enalapril on mortality and the development of heart failure in asymptomatic patients with reduced left ventricular ejection fractions. N Engl J Med. 1992;327(10):685691. doi:10.1056/NEJM199209033271003

31. Cohn JN, Tognoni G. A randomized trial of the angiotensin-receptor blocker valsartan in chronic heart failure. $N$ Engl J Med. 2001;345 (23):1667-1675. doi:10.1056/NEJMoa010713

32. Young JB, Dunlap ME, Pfeffer MA, et al. Mortality and morbidity reduction with candesartan in patients with chronic heart failure and left ventricular systolic dysfunction: results of the CHARM low-left ventricular ejection fraction trials. Circulation. 2004;110(17):26182626. doi:10.1161/01.CIR.0000146819.43235.A9

33. Zannad F, McMurray JJ, Krum H, et al. Eplerenone in patients with systolic heart failure and mild symptoms. N Engl J Med. 2011;364 (1):11-21. doi:10.1056/NEJMoa1009492

34. Digitalis Investigation Group. The effect of digoxin on mortality and morbidity in patients with heart failure. $N$ Engl J Med. 1997;336 (8):525-533. doi:10.1056/NEJM199702203360801

35. Ahmed A, Rich MW, Fleg JL, et al. Effects of digoxin on morbidity and mortality in diastolic heart failure: the ancillary digitalis investigation group trial. Circulation. 2006;114(5):397-403. doi:10.1161/ CIRCULATIONAHA.106.628347

36. Swedberg K, Komajda M, Böhm M, et al. Ivabradine and outcomes in chronic heart failure (SHIFT): a randomised placebo-controlled study. Lancet. 2010;376(9744):875-885. doi:10.1016/S0140-6736(10)61198-1

37. Díez J. Chronic heart failure as a state of reduced effectiveness of the natriuretic peptide system: implications for therapy. Eur J Heart Fail. 2017;19(2):167-176. doi:10.1002/ejhf.656

38. Gerber Y, Weston SA, Redfield MM, et al. A contemporary appraisal of the heart failure epidemic in Olmsted County, Minnesota, 2000 to 2010. JAMA Intern Med. 2015;175(6):996-1004. doi:10.1001/ jamainternmed.2015.0924

39. Entresto (sacubitril and Valsartan) [prescribing Information]. East Hanover, NJ: Novartis Pharmaceuticals Corporation; 2015.

40. Gu J, Noe A, Chandra P, et al. Pharmacokinetics and pharmacodynamics of LCZ696, a novel dual-acting angiotensin receptor-neprilysin inhibitor (ARNi). J Clin Pharmacol. 2010;50(4):401-414. doi: $10.1177 / 0091270009343932$

41. McMurray JJ, Packer M, Desai AS, et al. Dual angiotensin receptor and neprilysin inhibition as an alternative to angiotensin-converting enzyme inhibition in patients with chronic systolic heart failure: rationale for and design of the prospective comparison of ARNI with ACEI to determine impact on global mortality and morbidity in heart failure trial (PARADIGM-HF). Eur $J$ Heart Fail. 2013;15(9):1062-1073. doi:10.1093/eurjhf/hft052

42. Iborra-Egea O, Gálvez-Montón C, Roura S, et al. Mechanisms of action of sacubitril/valsartan on cardiac remodeling: a systems biology approach. NPJ Syst Biol Appl. 2017;3:12. doi:10.1038/s41540-017-0013-4 
43. Entresto FDA 207620 [approval letter]; July 7, 2015. Available from: https://www.accessdata.fda.gov/drugsatfda_docs/appletter/2015/ 207620Orig1s0001tr.pdf. Accessed July 19, 2018

44. Entresto [summary of Product Characteristics]. Nuremberg, Germany: Novartis Pharma GmbH; 2015.

45. McMurray JJ, Packer M, Desai AS, et al. Angiotensin-neprilysin inhibition versus enalapril in heart failure. $N$ Engl J Med. 2014;371 (11):993-1004. doi:10.1056/NEJMoa1409077

46. Claggett B, Packer M, McMurray JJ, et al. Estimating the long-term treatment benefits of sacubitril-valsartan. $N$ Engl J Med. 2015;373 (23):2289-2290. doi:10.1056/NEJMc1509753

47. Sandhu AT, Ollendorf DA, Chapman RH, Pearson SD, Heidenreich PA. Cost-effectiveness of sacubitril-valsartan in patients with heart failure with reduced ejection fraction. Ann Intern Med. 2016;165 (10):681-689. doi:10.7326/M16-0057

48. Desai AS, McMurray JJ, Packer M, et al. Effect of the angiotensinreceptor-neprilysin inhibitor LCZ696 compared with enalapril on mode of death in heart failure patients. Eur Heart J. 2015;36 (30):1990-1997. doi:10.1093/eurheartj/ehv186

49. Fonarow GC, Yancy CW, Hernandez AF, Peterson ED, Spertus JA, Heidenreich PA. Potential impact of optimal implementation of evidence-based heart failure therapies on mortality. Am Heart $J$. 2011;161(6):1024-1030.e1023. doi:10.1016/j.ahj.2011.01.027

50. Pun PH. The interplay between CKD, sudden cardiac death, and ventricular arrhythmias. Adv Chronic Kidney Dis. 2014;21(6):480 488. doi:10.1053/j.ackd.2014.06.007

51. Parham WA, Mehdirad AA, Biermann KM, Fredman CS. Hyperkalemia revisited. Tex Heart Inst J. 2006;33(1):40-47.

52. Bodey F, Hopper I, Krum H. Neprilysin inhibitors preserve renal function in heart failure. Int $J$ Cardiol. 2015;179:329-330. doi:10.1016/j. ijcard.2014.11.059

53. Packer M, McMurray JJ, Desai AS, et al. Angiotensin receptor neprilysin inhibition compared with enalapril on the risk of clinical progression in surviving patients with heart failure. Circulation. 2015;131(1):54-61. doi:10.1161/CIRCULATIONAHA.114.013748

54. Carson PE, Anand IS, Win S, et al. The hospitalization burden and post-hospitalization mortality risk in heart failure with preserved ejection fraction: results from the I-PRESERVE trial (irbesartan in heart failure and preserved ejection fraction). JACC Heart Fail. 2015;3(6):429-441. doi:10.1016/j.jchf.2014.12.017

55. Abrahamsson P, Dobson J, Granger CB, et al. Impact of hospitalization for acute coronary events on subsequent mortality in patients with chronic heart failure. Eur Heart J. 2009;30(3):338-345. doi:10.1093/eurheartj/ehn503

56. Solomon SD, Dobson J, Pocock S, et al. Influence of nonfatal hospitalization for heart failure on subsequent mortality in patients with chronic heart failure. Circulation. 2007;116(13):1482-1487. doi:10.1161/CIRCULATIONAHA.107.696906

57. Desai AS, Claggett BL, Packer M, et al. Influence of sacubitril/ valsartan (LCZ696) on 30-day readmission after heart failure hospitalization. J Am Coll Cardiol. 2016;68(3):241-248. doi:10.1016/j. jacc.2016.04.047
58. Kobalava Z, Kotovskaya Y, Averkov O, et al. Pharmacodynamic and pharmacokinetic profiles of sacubitril/valsartan (LCZ696) in patients with heart failure and reduced ejection fraction. Cardiovasc Ther. 2016;34(4):191-198. doi:10.1111/1755-5922.12183

59. Ponikowski P, Voors AA, Anker SD, et al. ESC Guidelines for the diagnosis and treatment of acute and chronic heart failure: the task force for the diagnosis and treatment of acute and chronic heart failure of the European Society of Cardiology (ESC). Developed with the special contribution of the Heart Failure Association (HFA) of the ESC. Eur J Heart Fail. 2016;18(8):891-975. doi:10.1002/ejhf.592

60. McMurray JJ, Packer M, Desai AS, et al. Baseline characteristics and treatment of patients in prospective comparison of ARNI with ACEI to determine impact on global mortality and morbidity in heart failure trial (PARADIGM-HF). Eur J Heart Fail. 2014;16(7):817-825. doi:10.1002/ ejhf.115

61. Jhund PS, Fu M, Bayram E, et al. Efficacy and safety of LCZ696 (sacubitril-valsartan) according to age: insights from PARADIGM-HF. Eur Heart J. 2015;36(38):2576-2584. doi:10.1093/eurheartj/ehv330

62. Solomon SD, Claggett B, Desai AS, et al. Influence of ejection fraction on outcomes and efficacy of sacubitril/valsartan (LCZ696) in heart failure with reduced ejection fraction: the prospective comparison of ARNI with ACEI to determine impact on global mortality and morbidity in heart failure (PARADIGM-HF) trial. Circ Heart Fail. 2016;9(3):e002744.

63. Simpson J, Jhund PS, Silva Cardoso J, et al. Comparing LCZ696 with enalapril according to baseline risk using the MAGGIC and EMPHASIS-HF risk scores: an analysis of mortality and morbidity in PARADIGM-HF. J Am Coll Cardiol. 2015;66(19):2059-2071. doi:10.1016/j.jacc.2015.08.878

64. Velazquez EJ, Morrow DA, DeVore AD, et al. Angiotensin-neprilysin inhibition in acute decompensated heart failure. $N$ Engl $J$ Med. 2019;380(6):539-548. doi:10.1056/NEJMoa1812851

65. Riddell E, Vader JM. Potential expanded indications for neprilysin inhibitors. Curr Heart Fail Rep. 2017;14(2):134-145. doi:10.1007/ s11897-017-0327-y

66. Vardeny O, Claggett B, Packer M, et al. Efficacy of sacubitril/valsartan vs. enalapril at lower than target doses in heart failure with reduced ejection fraction: the PARADIGM-HF trial. Eur J Heart Fail. 2016;18 (10):1228-1234. doi:10.1002/ejhf.580

67. Senni M, McMurray JJ, Wachter R, et al. Initiating sacubitril/valsartan (LCZ696) in heart failure: results of TITRATION, a double-blind, randomized comparison of two uptitration regimens. Eur $J$ Heart Fail. 2016;18(9):1193-1202. doi:10.1002/ejhf.548

68. Roche SL, Timberlake K, Manlhiot C, et al. Angiotensin-converting enzyme inhibitor initiation and dose uptitration in children with cardiovascular disease: a retrospective review of standard clinical practice and a prospective randomized clinical trial. J Am Heart Assoc. 2016;5(5):pii: e003230. doi:10.1161/ JAHA.116.003230
Vascular Health and Risk Management

\section{Publish your work in this journal}

Vascular Health and Risk Management is an international, peerreviewed journal of therapeutics and risk management, focusing on concise rapid reporting of clinical studies on the processes involved in the maintenance of vascular health; the monitoring, prevention and treatment of vascular disease and its sequelae; and the involvement of metabolic disorders, particularly diabetes. This journal is indexed on PubMed Central and MedLine. The manuscript management system is completely online and includes a very quick and fair peerreview system, which is all easy to use. Visit http://www.dovepress. com/testimonials.php to read real quotes from published authors. 